\title{
Methodological approaches to the study of socio-economic constraints on sustainable development of the Karelian Arctic region in modern conditions
}

\author{
Aleksander Volkov ${ }^{1, *}$ \\ ${ }^{1}$ Institute of Economics of the Karelian Research Centre of the Russian Academy of Sciences, 50 A. \\ Nevsky Ave., Petrozavodsk, Republic of Karelia, Russia, 185030
}

\begin{abstract}
The article examines the tools of sociological research, used in the study of the state and prospects of the socio-economic and environmental development of the Karelian Arctic region, its human capital, as a factor in the sustainable development of the region. Special attention is paid to the reasons for choosing migration from the region of residence as a form of investment in the human capital, as well as the role of a wide range of factors in deciding on migration, such as environmental, economic and social ones. The tasks of a comprehensive study of the processes of regional socio-economic and ecological development are considered, the methodological approaches used at each stage of this study are determined, the importance of sociological tools in the system of goals and objectives of this study is identified. The process of forming a special economic and legal regime of the Arctic Zone of the Russian Federation as a whole and the Karelian Arctic region requires taking into account not only the entire spectrum of the latest problems of these territories, but also updating the knowledge about the features of their socio-economic and ecological economic development. These circumstances require the improvement of research tools used in the study of these processes.
\end{abstract}

\section{Introduction}

The development of the Arctic zone of Russia is currently one of the priorities of the state policy [1]. The major significance of this region, both for the internal development of the country and in the foreign policy and economic relations, requires balanced government decisions made on a solid scientific basis. The latest economic, environmental and political challenges, as well as changes in the borders of the Arctic zone itself, which in recent years has turned into a separate object of state management [2], determine the need for new studies of the spatial development of the region's economy and improving their tools. The object of this study is the territory of the Karelian Arctic, formed due to six municipalities of the Republic of Karelia entering the Arctic zone of Russia (AZRF): on June 27, 2017, Loukhsky, Kemsky and Belomorskydistricts became part of the AZRF, on July 7, 2020 -

*Corresponding author:kov8vol@gmail.com 
Kalevalsky and Segezhsky districts, as well as the urban district of Kostomuksha.The subjects of this study are therelations that make up the processes of the ecological economic and socio-economic development of the region and the reproduction of human capital.The goal of this study isto form research tools for studying the latest trends in the socioeconomic and ecological economic development of the Karelian Arctic region, aimed also at identifying the place and significance of human capital in the system of restrictions on the sustainable regional development of the Karelian Arctic.At the same time, the adaptation of the mechanisms of state management of the development of the Arctic zone of Russia to the newly included regions remains a topical issue of research in the field of regional and spatial economics. A number of key aspects determine the relevance of this issue:

- the need for an objective analysis of the present conditions and resources for the implementation of projects and programs in these territories (natural resources, industrial potential, infrastructure provision, human capital)

- the importance of assessing the level of awareness of local government representatives and regional authorities about the existing instruments for regional development of the territories of the Russian Arctic.

- the need to identify priority development projects for these territories, the specifics of the regulatory impact on them, the amount of allocated budget funds in order to maximize the systemic effect of the implementation of projects of integrated development of the Russian Arctic.

\section{Materials and methods}

To achieve the stated goal, a comprehensive toolkit was developed, which includes a specialized methodologyfeaturing a synthesis of qualitative and quantitative methods. Among the approaches and methods used, the dialectical approach and the systemic approach are especially noteworthy; theyinclude the following methods used: statistical analysis, institutional analysis, a set of sociological research methods (semi-formalized expert interview, survey of the population), methods of factorial and cluster analysis of the data obtained, the method of content analysis. In the development of this toolkit, the already existing developments of Russian scientists played a decisive role. Studies of the spatial development of the AZRF have a long history that comes to life in the works of A. Tatarkin. [3], S. Agarkov [4], B. Porfiriev [5], V. Selin[6] and other economists.

In the study of the latest problems of the development of the Russian Arctic, Russian scientists successfully apply sociological research methods [7-11].

We do not deny the importance of economic and statistical analysis in solving the aforementioned crucial issues, however, in this study, we will pay special attention to sociological methods (the methods of interviewing and questioning) of studying the issues of socio-economic and ecological economic development of the territories, the implementation of the support zone project for the development of the Arctic and the spread of a special economic regime. These methods are being implemented in the current research conducted by the author on the territory of the Arctic Karelia region.

\section{Results and discussion}

\subsection{The general approaches to the development of tools for a comprehensive study, the use of the expert survey method}

The developed toolkit reflects the stages of fulfilling the research goal and is used accordingly in the execution of the following tasks: 
1. Identification of the main trends in the regional development of the Karelian Arctic in the years 2008-2020 (collecting the statistical data, formatting itfor comparison and analyzing it - methods of statistical analysis).

2. Analysis of the existing results framework in the development of the Karelian Arctic and the Russian Arctic as a whole (analysis of the program documents for regional development at the level of the Karelian Arctic and the Russian Arctic, the legal framework for economic development, state target programs, special tax regimes in these territories, etc.)

3. Analysis of the experience of implementing special economic regimes in the Russian Arctic and the Karelian Arctic in particular, as well as the realization progress of the project "Support zones for the development of the Arctic", analysis of the funds allocated for the implementation of this project from the federal budget (an analysis of the official information on the implementation of projects of special economic regimes).

4. An expert survey of local government representatives and regional authorities of the Republic of Karelia on the existing trends in the socio-economic development of the municipalities of the Republic of Karelia included in the AZRF, on the development of the main industries, the situation on the labor market in the employment sector, the professions in demand, the labor force dynamics, as well as on the awareness of local government representatives about the projects and program events in the development of the Russian Arctic. An expert survey of representatives of the leading enterprises in the Karelian Arctic on the prospects for the ecological and economic development of these enterprises and single-industry towns, on the effectiveness of support measures from the regulation entities, the development restrictions and ways to solve personnel shortage problems, etc. (the method of semi-formalized interviews, transcription of audio recordings, analytical processing, and, in some cases, a content analysis of transcriptions).

5. Asociological survey of the population of the Karelian Arctic in order to supplement the quantitative data on the main trends in the development of the human capital in the region with information on the individual strategies for the development of human capital, economic practices and forms of investment in the human capital, the attitudes towards migration, the education and qualifications of the respondents, as well as the compliance of the current place of work and position with theprofession (the method of formalized interviewing, development of a layout and entering the data into the SPSS system).

6. Construction of a typology of the population behavior in the field of investment in the human capital and its development (one-dimensional and multidimensional analyses of the data obtained as a result of a sociological survey).

7. Identification of the existing prerequisites for the development, potential, strengths and weaknesses of the regional socio-economic system of the Karelian Arctic from the point of view of integration into the process of complex development of the Russian Arctic, including in the format of the"Support zones for development" (a SWOT analysis of the territorial entity of the Karelian Arctic based on the data from expert surveys of local government representatives and representatives of enterprises, as well as on the statistical information on the socio-economic development of the region).

8. Determination of the system of restrictions on the regional development of the Karelian Arctic, development of measures to overcome them, including those based on the use of the human capital of the region and the transition to its expanded reproduction (generalization of the results of the implementation of the previous tasks, an economic analysis).

Consistent performance of these tasks and use of appropriate tools will qualitatively expand and improve the available scientific knowledge about the Karelian Arctic region, its human capital, existing trends in the socio-economic and ecological economic development of the region, its potential, strengths and weaknesses in terms of transitioninginto an 
innovative development model and its inclusion in complex development projects of the Russian Arctic.

The subjects of the survey are the representatives of the municipal district administrations of the Republic of Karelia that are part of the Arctic zone. The main purpose of the expert survey is to obtain up-to-date information on the existing resources for the implementation of long-term development programs for the Arctic zone of Russia (AZRF) in the context of the inclusion of the municipalities of the Republic of Karelia into the Arctic zone and the formation of the Arctic Karelia region.

We consider the expert survey as an auxiliary tool for studying the socio-economic and ecological economic processes in the region.

An expert survey of the local government representatives of these regions will allow us to supplement the statistical analysis with qualitative information, due to:

1.Correct and objective interpretation of the statistical data, especially with sharp annual changes in the indicators, their uncharacteristic dynamics, incompleteness of data and their incomparability over time.

2. Time coverage of the states of the object of expert assessment. In the current context of the global challenges and macroeconomic shocks, represented by the long-term impact of the COVID-19 pandemic, the unfavorable conjuncture of the energy markets, the building momentum of the "energy transition" in the countries that are traditional consumers of Russian-made energy and the political instability in the world and the CIS countries, as well as the changes in the borders of the Arctic zone itself (occurring due to the inclusion of land areas in the AZRF), significant changes for analysis and understanding of the state of the object of study occurred within six months. The statistical data objectively lag behind in recording data on the state of the system over such a short period of time and with key and shock events for the socio-economic system happening this frequently. In this regard, the data of the expert assessment of specialists, heads of municipal districts and their deputies will make it possible to form the most objective idea of the latest trends in the development of the regions included in the Karelian Arctic.

Apart from adding qualitative information to the statistical data, an expert survey of representatives of local governments will reveal the following data that are important in the context of adaptation of Arctic projects in the emerging Karelian Arctic:

1. The degree of awareness of the local government bodies about the ongoing projects for the development of the Russian Arctic. Full and objective awareness of the local government bodies in these issues is important due to their functions in interacting with investors and entrepreneurs at the local level, in particular, receiving applications, assistance in preparing documents for competitive programs that provide financial support to businesses, etc.

2. Information about the upcoming investment projects that are under discussion with the investor or in the stage of document preparation.

3. Information about informal institutions that have developed in the local business environment and the relationships between the government, business and society.

Based on the specified purpose of using the toolkit, the sampling criteria were formed;dedicated experts, three specialists from the municipal administrations (generally, they were the heads of districts, their deputies and heads of Economic Development Departments) from each district were asked the following questions:

1. Whatis the tourism potential of the region in your opinion, and what is its strong point?

2. Name the weak components of the tourism potential of the region in your opinion.

What is lacking for the development of the industry?

3. How would you briefly describe the development of the tourism sector over the past 12 years? 
4. What, in your opinion, is the fishery potential of the region? What are the strengths of the industry?

5. What are the weak components of the fishery potential of the region, in your opinion? What is lacking for the development of the industry?

6. How would you briefly describe the development of the fishing industry over the past 12 years?

7. What, in your opinion, is the industrial potential of the region and what is its strong point?

8. What are the weak components of the industrial potential of the region, in your opinion? What is lacking for the development of the industry?

9. How would you briefly describe the development of industry over the past 12 years?

10. Can you highlight any existing or promising projects in these areas that are being implemented in cooperation with neighboring areas or regions of the Arctic?

11. What are the main environmental problems of the district that you can name?

12. What types of negative impact do businesses in the district have on the environment?

a) groundwater pollution

b) pollution of water bodies and surface waters

c) soil pollution

d) landfills for technical waste

e) air pollution

f) other (specify)

13. Does the enterprise in the district implement programs to eliminate or reduce previously accumulated environmental pollution?

14. What are the most significant problems in the field of infrastructure (transport, heat supply, electricity supply) that you can currently highlight in your district?

15. What measures in the field of business support and economic developmentare being implemented in your district?

16. How often do entrepreneurs use the help of these measures?

a) Always

b) Very often

c) Often

d) Sometimes

e) Rarely

f) Very rarely

g) Never

17. Do you know about the "Support zones for development" project?

a) Yes, I do

b) No, I do not

18. How do you assess the effectiveness of the implemented state programs for the Arctic zone in your district?

a) High

b) Good

c) Medium

d) Low

e) Almost no effect

f) The implementation of the state programs did not affect the economy and society of the district.

19. Has anything changed in the economic and social situation of the district after its inclusion into the Arctic zone of the Russian Federation?

20. Which industry is the most promising for the development of the district?

21. How would you describe the workforce and employment of the district? 
22. How is the shortage of labor resources in the high-demand areas in your district compensated for?

23. How often do local people who leave to study in other cities return to the district to work?

24. Are there programs for retraining people who have lost their jobs and whose professions have remained unclaimed here?

25. What measures are planned to be taken at the administrative level to overcome the determined problems in the field of labor and employment?

\subsection{Methodological aspects of the implementation of the method of survey of the population}

Within the framework of the application of the research tools of the survey of the population, the following main tasks are solved:

- identification of social and economic characteristics of population groups prone to migration

- identification of social and economic characteristics of population groups in compliance with the division into the economically active and the economically inactive population

- identification of existing ecological economic practices of the population of Arctic Karelia.

The sample provides for a survey of 1100 respondents in the urban district of Kostomuksha (220 respondents) and five municipal districts of Arctic Karelia: Segezhsky municipal district (250 respondents), Belomorsky district (180 respondents), Kemsky district (180 respondents), Loukhsky district (150 respondents) and Kalevalsky district (120 respondents), in accordance with the size of the population of each municipal district and its demographic characteristics.

As part of completingthe first of theaforementioned tasks, the respondents are divided into groups according to the degree of their propensity to migrate, with the subsequent identification of the "portrait" of each group (age group, gender, compliance of the workplace to the academic degree, ability to plan their income in the place of residence, planned measures to increase the income and additional practices for reproducing human capital (part-time jobs, additional income, non-monetary benefits, etc.)) (Figure 1). From there, the people prone to migration are also split into groups by their reasons for migration (based on the data on question 15 of the survey).

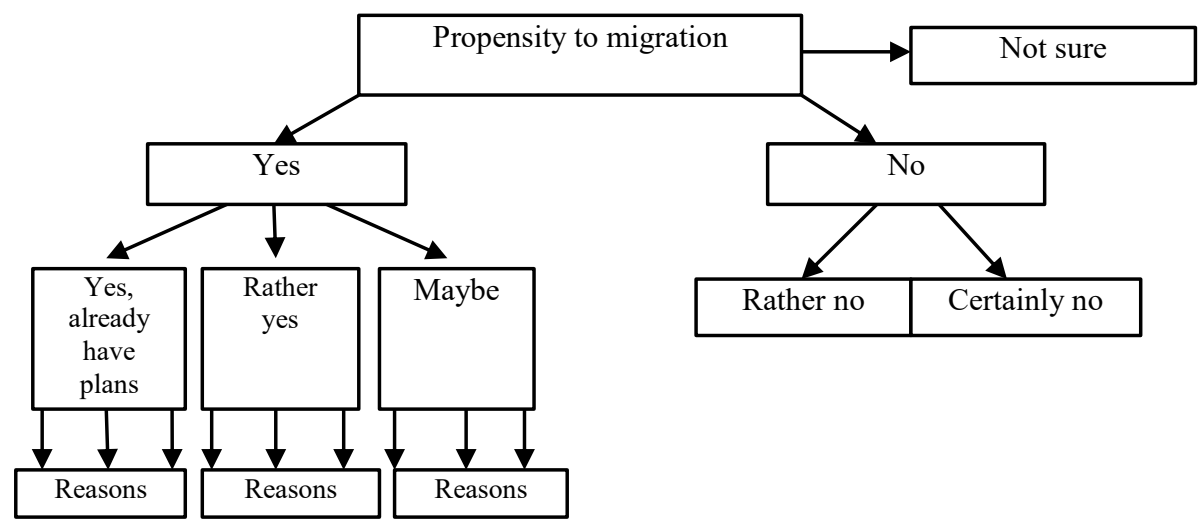

Fig. 1.Typology of respondents by the propensity to migrate. 
As part of completing the second task, a typology of the surveyed population of Arctic Karelia is provided in accordance with the following structure (Figure 2).

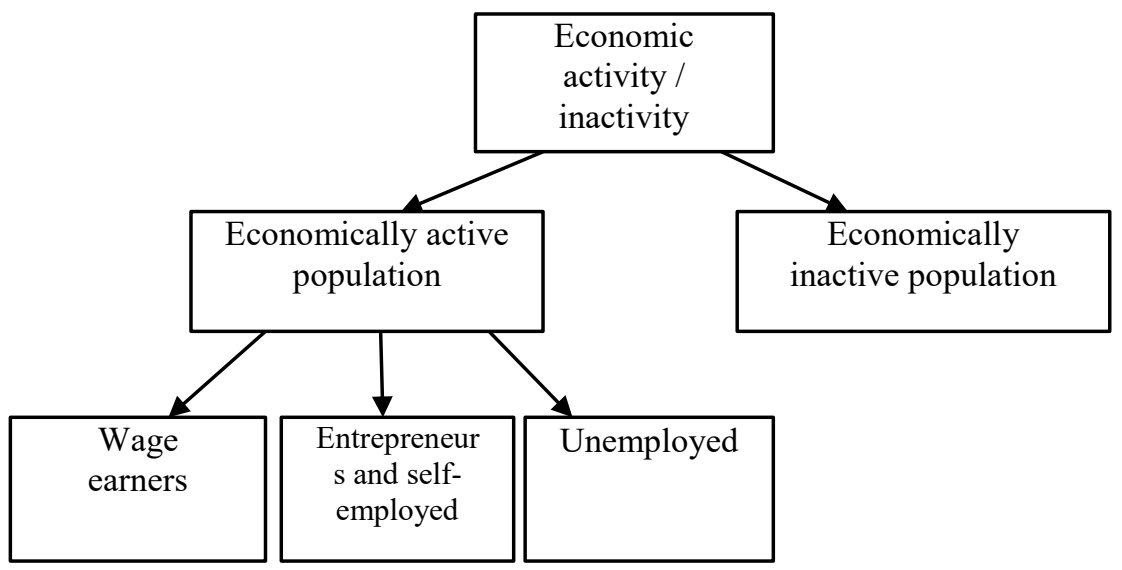

Fig. 2. Typology of respondents by the nature of the population's economic activity.

It is also implied that each group will be described based on gender, age, personal income, sources of income and attitudes toward migration.

As part of completing the third task, it is proposed to study the influence of environmental motives on the economic behavior of individuals in accordance with the following logical approach (Figure 3). When forming the questionnaire, we took into account the works of researchers from Lithuania and Finland in the field of research on environmental practices of the population [12-14].

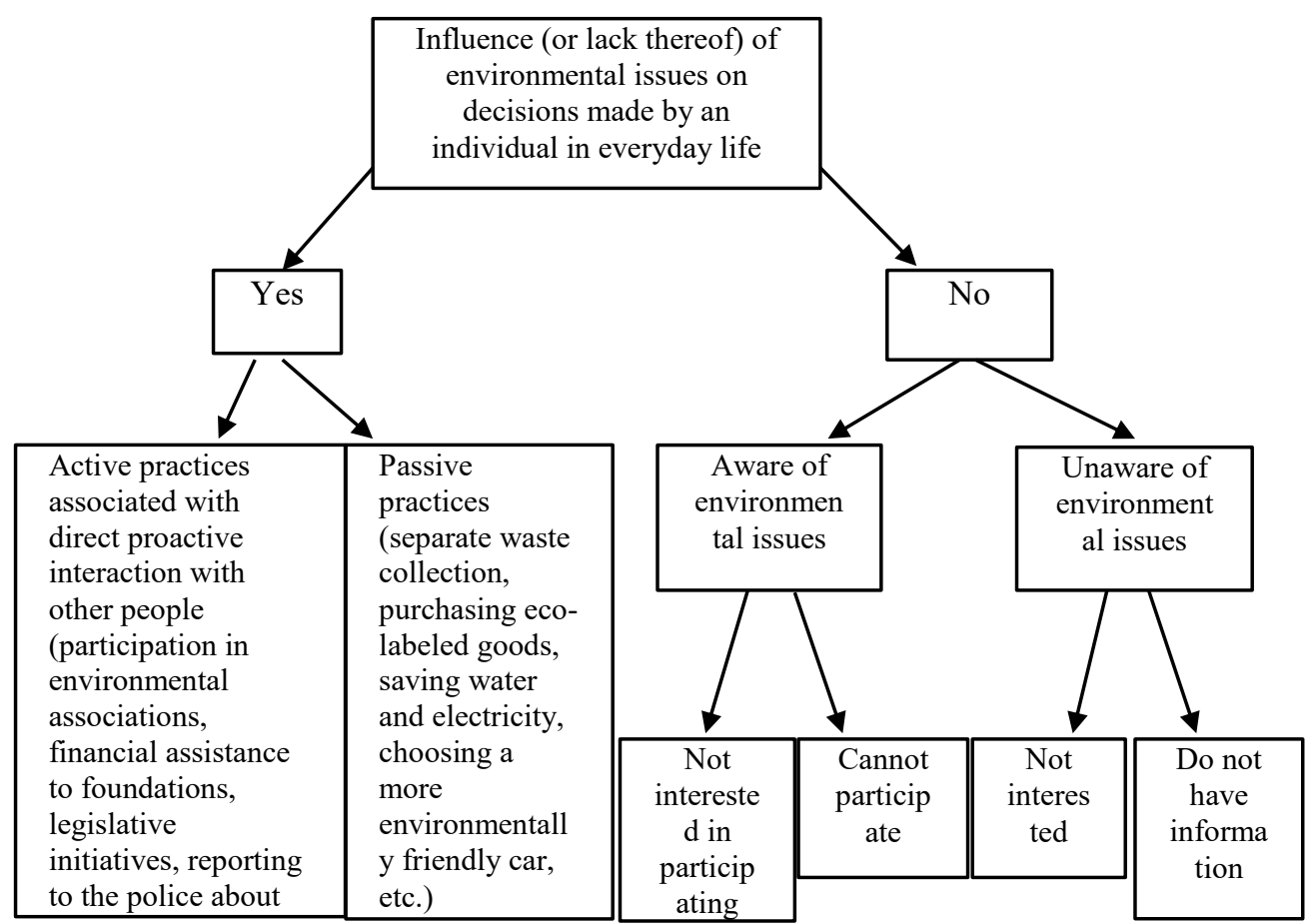

Fig. 3.Typology of respondents according to the degree of influence of environmental motives on the economic behavior of an individual. 
As part of completing this task, it is proposed to build a typology of the surveyed population based on the summation of the scores assigned to each ecological economic practice, depending on its nature.

\section{Conclusion}

The developed toolkit for a comprehensive socio-economic and ecological economic research corresponds with the urgent problems of regional development of the Karelian Arctic. In this toolkit, the survey of representatives of the local governments of the regions of Arctic Karelia using the expert interview tools will allow solving the following research tasks:

- Identify the latest trends in the development of the main industries (the fishing industry, mining and processing industry, tourism) and determine the most promising lines of the development of regions.

- Identify the main environmental problems and constraints that exist in the development of these industries.

- Determine the main pressing problems that hinder the development of these industries.

- Identify the latest trends in the emergence of interdistrict and interregional projects in the development of the economy of the Russian Arctic.

- Determine the level of awareness of local government specialists about the existing federal state projects in the Russian Arctic, in particular, about the project "Support zones for development".

- Determine the main problems of the regions in the field of employment and labor resources, existing practices for their solutionand the sufficiency of the human capital of Arctic Karelia for the implementation of complex projects for the development of the Russian Arctic on its territory.

The survey of the local population will allow solving the following research tasks:

- Identification of social and economic characteristics of population groups prone to migration

- Identification of social and economic characteristics of population groups in compliance with the division into economically active and economically inactive population

- Identification of existing ecological economic practices of the population of Arctic Karelia.

As part of the further development of research tools, it is planned to develop guidelines for interviews with representatives of major enterprises influencing the socio-economic and ecological economic development of Arctic Karelia, as well as representatives of environmental organizations and activists.

The study was conducted within the framework of the state assignment of the Ministry of Science and Higher Education of the Russian Federation "Institutions and social inequality in the context of global challenges and regional restrictions (0218-2019-0090)"

\section{References}

1. A.O. Podoplekin, K.G. Bulletin of the Northern (Arctic) Federal University Series "Humanities and Social Sciences",6, 36-46 (2014)

2. T.P. Skuf'ina The Russian, The Arctic: innovative technologies, personnel, tourism: Materials of the international scientific and practical conference under general editorship of V. I. Pryadkin, 173-176 (2018) 
3. A.I. Tatarkin, V.V. Litovskiy MSTU Bulletin,3, 573-587 (2014)

4. S. A. Agarkov, V. F. Bogachev, V. I. Bogoyavlenskiy et al. Geoeconomic processes in the Arctic and the development of sea communications. (2014)

5. V.N. Leksin, B.N. Porfir'ev Problems offorecasting, 6, 4-22 (2019)

6. N.I. Komkov, et al. Problems of forecasting, 1, 41-49 (2017)

7. S.V. Baranov, T.P. Skufina, I.A. Gushchina Economic and social changes: facts, trends, forecast, 1, 160-173 (2020)

8. I.A. Gushchina, D.L. Kondratovich, O.A. Polozhentseva Bulletin of the Altai Academy of Economics and Law,11-1, 48-53 (2019)

9. D.L. Kondratovich Economy vector, 12 (42), 63 (2019)

10. V. V. Markin, A. N. Silin, Economic and social changes-facts, trends, forecast, 10 Iss. 6, 75-88 (2017)

11. A.O. Podoplekin Arctic and North, 24, 27-39 (2016)

12. G. Liobikiene et al,Journal of Cleaner Production, 142, 3789-3797 (2017)

13. H. Hartikainen et al,Journal of Cleaner Production, 73,285-293 (2014)

14. Gorokhova T, et al. E3S Web of Conferences 135, 04069 (2019) doi:10.1051/e3sconf/201913504069 